\title{
Black coated tongue in integrative medicine: An alarm signal
}

\author{
Gislaine Cristina Abe ${ }^{1 *}$, Paulo Eduardo Ramos ${ }^{1}$, Bruna lourenço da Silva ${ }^{1}$, Acary Souza Bulle Oliveira ${ }^{1}$ \\ ${ }^{1}$ Division of Neuromuscular Disease Investigation, Department of Neurology, Universidade Federal de São Paulo, São Paulo, SP, Brazi
}

Study conducted at Universidade Federal de São Paulo (Unifesp),

São Paulo, SP, Brazil

Article received: $10 / 14 / 2015$

Accepted for publication: 11/1/2015

*Correspondence:

Address: Rua Estado de Israel, 899,

Vila Mariana

São Paulo, SP - Brazil

Postal code: 04022-000

gislaineabe@hotmail.com

http://dx.doi.org/10.1590/1806-9282.62.09.822

\section{INTRODUCTION}

In integrative medicine (IM), western medicine (WM) is associated with other non-conventional medicines, provided these are based on scientific evidence. ${ }^{1}$ All events are considered as part of the individual's health/disease process, which includes physical, mental, emotional and environmental factors. Traditional chinese medicine (TCM) includes the inspection of the tongue as an important means for diagnosis and prognosis of disease. ${ }^{2}$

In WM, black coated tongue is associated with smoking, the use of medication such as antibiotics or corticosteroids, radiotherapy, or poor oral hygiene. It is considered a benign change resulting from decreased apoptosis of the epithelium on the dorsum of the tongue, with consequent elongation of the papillae and modification of the local flora, with an increase of fungi and chromogenic bacteria. ${ }^{3-5}$ Resolution is spontaneous, or involves removal while brushing the teeth and tongue. ${ }^{4}$ In TCM, however, it has another meaning. It demonstrates a state of internal heat ${ }^{2}$ with extreme decompensation of the internal equilibrium, with a tendency towards the emergence of diseases., ${ }^{2,6}$

\section{Case report}

A 72-year-old female patient had a photo of her tongue recorded during a tongue inspection course. Darkened, blackish-looking coating was seen in the posterior region of the tongue, and she was sent for monitoring. There was also a severe deviation of the tongue to the left. This procedure was adopted in the service after a case monitored in the outpatient clinic, reported in an article published in 2014. ${ }^{7}$ She had no current complaints, except a burning sensation on the tongue for a year, which she considered normal.

She reported initial insomnia with interruptions due to nocturia, diabetes mellitus type 2 currently controlled with a hypocaloric diet, and metrorrhagia, with a diagnosis of uterine fibroids, submitted to partial hysterectomy at 46 years of age. Also at age 46 , she presented suppurative appendicitis and underwent appendectomy. At the age of 62 years, she began to present right-sided flank pain with increased flatulence and alternation between diarrhea and intestinal constipation not related to food. The patient was diagnosed with idiopathic ulcerative rectocolitis. She used oral cortisone for 3 years. She is currently under medical monitoring, with annual control, without the use of medication. At the age of 70 years, she had two non-malignant polyps removed from her stomach. She currently uses vitamin D weekly for replenishment, omega 3, 6 and 9 and coenzyme Q10.

On physical examination, she presented a distended abdomen, tympanic to percussion, with diffuse light pain on deep palpation. The tongue was diverted with a black coating in the posterior region (root) (Figure 1).

\section{Discussion}

Inspection of the tongue has been carried out for a long time in WM. Several studies have described the atypical features of the tongue. ${ }^{3-5}$ Some are observed in diseases, such as pale color of the tongue or lack of taste in anemia, and macroglossia in Down's syndrome and hypothyroidism. ${ }^{8}$ However, many conditions, such as geographic tongue, fissures and abnormal coatings have been con- 
sidered as benign and without clinical significance up to now. ${ }^{3-5}$ Black coated tongue is reported as a nonspecific change in some pathological conditions, but its etiopathogenesis is still unclear. In TCM these characteristics (and many other) inform the state of the internal functioning, guiding the diagnosis, prognosis and treatment of diseases. ${ }^{2,6,9}$

It is possible to assess risk situations with a systematic assessment of the tongue's characteristics. ${ }^{10}$ Although the patient did not have a current complaint, her personal and family history indicate the need for periodic medical

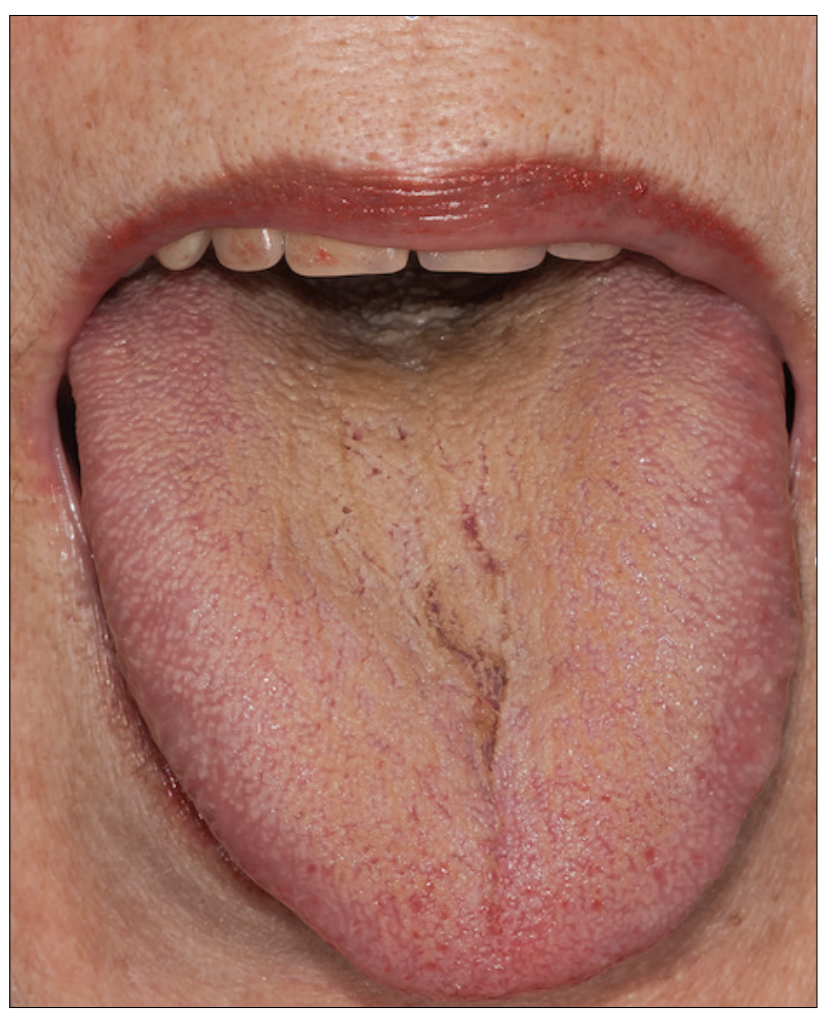

monitoring, with investigations for tumor markers, which was already undertaken some years ago (Chart 1).

Clinical monitoring was undertaken without intervention. After 3 months, there was worsening of abdominal pain, and a digestive endoscopy showed nonerosive distal esophagitis, hiatal hernia with minor sliding, and mild antral erosive gastritis. Eight months after the first assessment, the doctor undertaking routine monitoring requested control tests that revealed high tumor markers CEA, CA 19-9 and CA 125 (Chart 1). This motivated the request for imaging examinations to investigate tumors in the abdomen and central nervous system (ultrasound and tomography of abdomen and skull), which were normal. Clinically, she presented worse abdominal and lower back pain.

Given the overall clinical assessment, no medication was prescribed. In the TCM assessment there was need for intervention based on the history and evolution of the signs and symptoms, as the bizarre changes to the tongue in this patient indicated possible reactivation of ulcerative rectocolitis or even the appearance of tumoral processes. ${ }^{11,12}$ The patient underwent abdominal massage (Qi Nei Zang) and systemic acupuncture. After 2 months of treatment, there was less abdominal pain and the examinations normalized (Chart 1). The coating of the tongue became yellow (Figure 2), which shows disease regression, albeit without normalization of the internal heat. According to the clinical parameters and appearance of the tongue, ${ }^{11}$ we believe the patient is no longer in a condition of instability and risk of harm, but should still continue the treatment. The "spontaneous" resolution of black coated tongue stated by several authors indicates that the process changes over time, with clinical improvement or worsening, depending on the interventions carried out.

FIGURE 1 Tongue with black coating in the posterior region, and deviation to the left.

CHART 1 Medical monitoring of tumor markers between 2013 and 2015.

\begin{tabular}{|c|c|c|c|c|c|}
\hline Tests (normal values) & Dates & & & & \\
\hline & $1 / 16 / 2013$ & $5 / 13 / 2013$ & $7 / 20 / 2013$ & $1 / 24 / 2015^{*}$ & $4 / 17 / 2015^{* *}$ \\
\hline $\begin{array}{l}\text { CEA } \\
\text { (up to } 3 \mathrm{ng} / \mathrm{mL} \text { ) }\end{array}$ & - & 4.4 & 5.5 & 6.2 & 4.6 \\
\hline $\begin{array}{l}\text { CA } 19-9 \\
\text { (up to } 3.5 \mathrm{U} / \mathrm{mL} \text { ) }\end{array}$ & 54.5 & 31.8 & 31.9 & 51.8 & 24.6 \\
\hline $\begin{array}{l}\text { CA } 125 \\
\text { (up to } 35 \mathrm{U} / \mathrm{mL} \text { ) }\end{array}$ & 5.7 & 5.4 & - & 6.8 & 5.7 \\
\hline
\end{tabular}

*Tumor markers previously to intervention; **tumor markers 2 months after treatment with acupuncture and abdominal massage (Qi Nei Zang). 


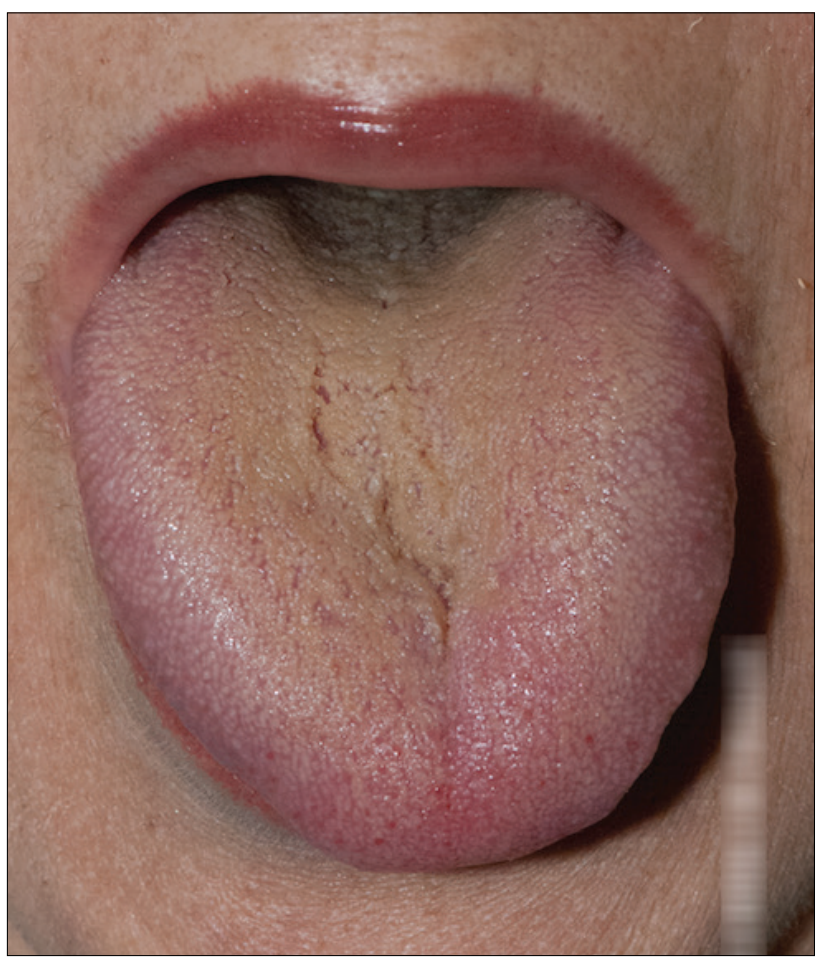

FIGURE 2 Tongue with diffuse yellow coating, with a slight deviation to the left.

\section{REFEREnCES}

1. Lima PT. Medicina Integrativa e a cura pelo equilíbrio. São Paulo: MG Editores; 2009. p. 139.

2. Yamamura Y, Yamamura ES. Propedêutica energética da língua e pulsologia chinesa. São Paulo: Center AO; 2009. p. 67-274.

3. Laskin DM, Giglio JA, Riper ET. Differential diagnosis of tongue lesions. Oral Pathol. 2003; 34(5):331-42.

4. McNally MA, Langlais RP. Conditions peculiar to the tongue. Dermatol Clin. 1996; 14(2):257-72.

5. Reamy BV, Derby R, Bunt CW. Common tongue conditions in primary care. Am Fam Physician. 2010; 81(5):627-34.

6. Fazel M. Now show me your tongue: a taste of medicine in China. Lancet. 1995; 346(8991-8992):1687-8.

7. Abe GC, Yonamine BTS, Mello CAS, Ramos PE, Conde MS, Oliveira ASB Acupuncture for treating persistent pain in Brazilian para-athletes. Med Acupunct. 2014; 26(1):50-6.

8. Maffei WE. Os fundamentos da medicina. 2. ed. São Paulo: Artes Médicas; 1978. p. 321.

9. Lu AP, Jia HW, Xiao C, Lu QP. Theory of traditional Chinese medicine and therapeutic method of diseases. World J Gastroenterol. 2004; 10(13):1854-6.

10. Abe GC, Ramos PE, Fontes SV, Pradella-Hallinan M, Oliveira ASB. Tongue inspection: a protocol to integrate neurology and traditional Chinese medicine. Rev Neurocienc. 2014; 22(2):201-14.

11. Lin SC, Chen MF, Li TC, Hsieh YH, Liu SJ. The distribution of Yin-Deficient symptoms and their relationship on survival rate in cancer patients with Yin-Deficiency. Am J Chin Med. 2008; 36(4):655-63.

12. Sun DZ, Liu L, Jiao JP, Wei PK, Jiang LD, Xu L. Syndrome characteristics of traditional Chinese medicine: summary of a clinical survey in 767 patients with gastric cancer. Zhong Xi Yi Jie He Xue Bao. 2010; 8(4):332-40. 